\title{
PENGARUH MODEL PEMBELAJARAN KOOPERATIF TIPE GROUP \\ INVESTIGATION (GI) TERHADAP HASIL BELAJAR SISWA \\ PADA MATERI POKOK SUHU DAN KALOR \\ DI KELAS X SEMESTER II DI SMAN 1 \\ PERCUT SEI TUAN T.P 2015/2016
}

\author{
Zulviana Oktari Saragi dan Khairul Amdani \\ Jurusan Fisika FMIPA Universitas Negeri Medan \\ Zulvianaoktari24@gmail.com
}

\begin{abstract}
ABSTRAK
Penelitian ini bertujuan untuk mengetahui pengaruh model pembelajaran kooperatif tipe Group Investigation (GI) terhadap hasil belajar pada materi pokok suhu dan kalor di kelas X semester II SMA Negeri 1 Percut Sei Tuan T.P 2015/2016. Penelitian ini termasuk jenis penelitian kuasi eksperimen dengan desain two group pretest-postest. Sampel penelitian terdiri dari dua kelas, yang terdiri dari 37 siswa kelompok eksperimen yang menerapkan model pembelajaran kooperatif tipe group investigation dan 38 siswa kelompok kontrol dengan pembelajaran konvensional. Pengambilan sampel berdasarkan teknik cluster random sampling dari populasi seluruh siswa kelas X. Hasil penelitian menunjukkan bahwa penggunaan model pembelajaran kooperatif tipe group investigation pada materi pokok suhu dan kalor di kelas X semester II SMA Negeri 1 Percut Sei Tuan T.P. 2015/2016 secara signifikan lebih berpengaruh dalam meningkatkan hasil belajar siswa.
\end{abstract}

Kata Kunci: Model pembelajaran kooperatif tipe group investigation, hasil belajar, dan suhu dan kalor.

\begin{abstract}
The purpose of this research was to find out the effect of cooperative learning model type of group investigation on student's learning outcomes in temperature and heat subject matter in class X even semester SMA Negeri 1 Percut Sei Tuan academic year 2015/2016. This research is a quasi experiment using two group pretest-posttest design. The research sample of two classes consist of 37 students in experiment class that using cooperative learning model type of group investigation and 38 students in control class that using conventional learning. The sampling based on random cluster sampling technique from all student population on class X.. The result showed that an application of cooperative learning model type of group investigation in temperature and heat subject matter in class X even semester SMA Negeri 1 Percut Sei Tuan academic year 2015/2016, significantly more effective to improve student's learning outcomes.
\end{abstract}

Keywords: Cooperative learning model type of group investigation,outcomes learning, temperature and heat. 


\section{PENDAHULUAN}

Muhibbinsyah (2003), belajar adalah key term, 'istilah kunci' yang paling vital dalam setiap dasar pendidikan. Suasana belajar yang dinamis dan menyenangkan merupakan kondisi esensial dalam proses pembelajaran. Perlu ditanamkan persepsi positif pada setiap diri siswa, bahwa kegiatan pembelajaran merupakan peluang bagi mereka untuk menggali potensi diri untuk kehidupannya kelak. Berhasil tidaknya pembelajaran tergantung pada guru dan siswa sebagai aktor dalam pembelajaran. Tingkat keberhasilan dan kesesuaian hasil belajar siswa sangat dipengaruhi oleh kinerja guru. Kriteria yang harus dimiliki guru yakni harus memiliki keterampilan mengajar, mengelola tahapan pembelajaran, memanfaatkan pendekatan, menggunakan metoda yang sesuai, dan mampu mengalokasikan waktu.

Salah satu mata pelajaran yang diajarkan pada tingkat SMA adalah fisika. Fisika sebagai ilmu dasar mempunyai andil yang besar dalam kemajuan ilmu pengetahuan dan teknologi. Hal ini ditandai berkembangnya teknologi di segala bidang yang menerapkan konsepkonsep fisika. Pembelajaran fisika dapat dilakukan dengan pengamatan langsung melalui indera manusia dan pengamatan tidak langsung melalui media atau alat bantu yang tepat. Kenyataan yang dihadapi dilapangan, masih banyak guru menggunakan pembelajaran yang belum sesuai dengan tujuan yang ingin dicapai. Guru masih lebih berfokus pada mengajar dari pada membelajarkan siswa, sehingga pencapaian tujuan jangka panjang seperti berfikir kritis, kreatif, kerjasama, dan kemampuan pemahaman konsep hampir terabaikan. Berdasarkan observasi awal yang dilakukan di SMA Negeri 1 Percut Sei Tuan pada kelas $\mathrm{X}$ melalui hasil wawancara kepada salah seorang guru fisika, dari 75 siswa yang dijadikan sampel hanya sekitar 15\% siswa-siswi yang menunjukkan minat dalam belajar fisika yang telihat dari keaktifan siswa selama pembelajaran berlangsung. Sisanya sebesar $85 \%$ lebih bersifat pasif. Kurangnya minat siswa ini juga disebabkan karena guru kurang melibatkan siswa dalam pembelajaran. Selain wawancara dengan guru mata pelajaran fisika, pembagian angket juga disebarkan kepada 35 siswa di kelas $\mathrm{X}$ saat observasi awal. Data yang diperoleh melalui angket menunjukkan bahwa $28 \%$ siswa menyukai pelajaran fisika, $42 \%$ siswa tidak menyukai pelajaran fisika, dan sisanya $30 \%$ menyatakan biasa saja. Saat diberikan pertanyaan mengenai seringnya guru mengaitkan materi dengan kehidupan sehari-hari diperoleh data sekitar $6 \%$ menyatakan selalu, 32\% pernah, 3\% tidak pernah, $59 \%$ sisanya menyatakan kadangkadang hanya pada materi tertentu. Berkaitan dengan pertanyaan cara belajar yang mereka inginkan, 53\% menyatakan praktikum dan demonstrasi, $16 \%$ menyatakan banyak mengerjakan soal dan diskusi kelompok, 25\% menyatakan bermain dan belajar, $6 \%$ sisanya menyatakan ceramah. Berdasarkan hasil observasi yang diperoleh, maka dibutuhkan suatu model pembelajaran yang tepat sebagai solusi untuk mengatasi permasalahan yang dihadapi guru. Model pembelajaran yang dapat menuntut siswa untuk dapat berperan aktif dalam pembelajaran. Salah satu kegiatan yang dapat dilakukan guru untuk meningkatkan minat belajar siswa yakni mempersiapkan pembelajaran dengan menggunakan perangkat pembelajaran yang lebih inovatif dan juga harus dapat merubah paradigma belajar yang lebih menyenangkan yang di dalamnya terintegasi nilai-nilai karakter. Sesuai dengan pilar-pilar belajar yang ada dalam 
kurikulum pendidikan kita dimana salah satu pilar belajar adalah belajar untuk membangun dan menemukan jati diri, melalui proses pembelajaran yang aktif, kreatif, efektif, dan menyenangkan (Permendiknas no 22 thn 2006).

Model pembelajaran yang menurut penulis efektif yaitu model pembelajaran kooperatif dengan tipe GI. Model pembelajaran kooperatif tipe GI tepat untuk mengatasi masalah di atas karena tujuan kognitif atau hasil dari GI adalah pengetahuan konseptual akademis (Arends, 2008). Model pembelajaran kooperatif tipe GI merupakan salah satu model pembelajaran yang dapat melibatkan siswa secara aktif sejak perencanaan pembelajaran, baik dalam menentukan topik yang akan dibahas maupun cara untuk mempelajarinya melalui investigasi kelompok sehingga dapat digunakan untuk mengatasi masalah pembelajaran fisika. Harapannya agar terjadinya pembelajaran bermakna sesuai dengan paradigma konstruktivistik. Artinya, dalam pembelajaran ini kegiatan aktif dan pengetahuan dibangun sendiri oleh siswa dan mereka bertanggung jawab atas hasil pembelajarannya.

Penelitian mengenai model pembelajaran kooperatif tipe GI sudah pernah diteliti oleh peneliti sebelumnya. Wahyuni, dkk (2014) diperoleh skor ratarata tes hasil belajar untuk pretest kelas eksperimen $=7,96$ dan kelas kontrol $=$ 6,80 . Hasil postes kelas eksperimen 11,50 dan kelas kontrol 9.08. Data ini menunjukkan bahwa model pembelajaran kooperatif dengan tipe GI efektif terhadap hasil belajar fisika pada siswa kelas XI MA Alkhairaat Kalangkangan. Penelitian yang dilakukan Sakinah (2014) diperoleh adanya pengaruh yang signifikan bahwa model pembelajaran kooperatif tipe GI terhadap hasil belajar siswa pada materi pokok suhu dan kalor di kelas X SMA
Negeri 1 Perbaungan. Berdasarkan data yang didapat, hasil nilai pretes kelas eksperimen diperoleh 35,46 dan postest 70,15. Kelemahan dari penelitian ini adalah peneliti masih kurang mampu mengelola waktu secara efisien, dan kurang baik dalam membuat perencanaan pada pengorganisasian kelompok. Penelitian yang dilakukan Priastuti (2015) juga menunjukkan adanya peningkatan hasil belajar siswa dengan menggunakan model pembelajaran kooperatif tipe GI terhadap hasil belajar siswa pada materi pokok besaran fisika dan satuannya di kelas X semester I SMA Negeri 1 Tanjung Tiram Batubara. Data yang diperoleh, hasil nilai pretes kelas eksperimen diperoleh 44,53 dan setelah diberikan perlakuan dengan menggunakan model pembelajaran kooperatif tipe GI nilai postes kelas eksperimen menjadi 77,66.

\section{TUJUAN PENELITIAN}

Tujuan penelitian ini adalah untuk mengetahui pengaruh model pembelajaran kooperatif tipe GI dan konvensional pada materi pokok suhu dan kalor pada Kelas X Semester II di SMA Negeri 1 Percut Sei Tuan T.P 2015/2016.

\section{METODE PENELITIAN}

Penelitian ini dilaksanakan di SMAN 1 Percut Sei Tuan pada semester II T.P. 2015/2016. Populasi dalam penelitian ini adalah seluruh siswa kelas X semester II SMA Negeri 1 Percut Sei Tuan. Sampel dalam penelitian ini terdiri dari dua kelas yang dipilih secara acak dengan teknik cluster random sampling yang melibatkan dua kelas yang diberi perlakuan berbeda. Kelas eksperimen dengan menggunakan model pembelajaran kooperatif tipe GI sedangkan di kelas kontrol menggunakan pembelajaran konvesional.

Penelitian ini termasuk jenis penelitian quasi eksperimen dan desain 
penelitian yang digunakan adalah two group pretest-postest design. Rancangan penelitian ini ditunjukkan pada Tabel 1 .

Tabel 1. Pretest-Posttest Design

\begin{tabular}{|l|c|c|c|}
\hline Kelas & Pretest & Perlakuan & Posttest \\
\hline Eksperimen & $\mathrm{O}$ & $\mathrm{X}$ & $\mathrm{O}$ \\
\hline Kontrol & $\mathrm{O}$ & $\mathrm{Y}$ & $\mathrm{O}$ \\
\hline
\end{tabular}

Keterangan:

$\mathrm{X}=$ model pembelajaran kooperatif tipe group investigation

$\mathrm{Y}=$ pembelajaran konvensional

$\mathrm{O}=$ instrumen/tes hasil belajar

Uji Lilliefors digunakan untuk mengetahui data populasi sampel-sampel yang secara teoritik sampai tak terhingga, berdistribusi normal. Uji homogenitas digunakan untuk mengetahui apakah data populasi sampel-sampel yang secara teoritik sampai tak terhingga berasal dari populasi yang homogen. Uji homogenitas menggunakan uji kesamaan varians. Pengujian hipotesis digunakan uji $t$ dengan rumus (Sudjana, 2005):

$$
t=\frac{\bar{X}_{1}-\bar{X}_{2}}{s \sqrt{\frac{1}{n_{1}}+\frac{1}{n_{2}}}}
$$

\section{HASIL DAN PEMBAHASAN Hasil Penelitian}

Penelitian ini melibatkan dua kelas yang diberi model pembelajaran yang berbeda yaitu pada kelas eksperimen menggunakan model pembelajaran kooperatif tipe GI dan pada kelas kontrol menggunakan pembelajaran konvensional. Sebelum ke dua kelas diberi perlakuan kedua kelas terlebih dahulu diberikan pretes yang bertujuan untuk mengetahui kemampuan awal siswa.

Berdasarkan hasil pretes yang diperoleh, nilai rata-rata pretes kelas eksperimen 34,95 dan nilai pretes kontrol
34,71. Selanjutnya kelas eksperimen dan kelas kontrol diberikan perlakuan yang berbeda. Kelas eksperimen menggunakan model pembelajaran kooperatif tipe GI dan pada kelas kontrol menggunakan pembelajaran konvensional. Setelah ke dua kelas diberi perlakuan, masingmasing kelas diberi postes untuk melihat adanya pengaruh akibat diberikan perlakuan pembelajaran yang berbeda. Dari data postes ke dua kelas diperoleh nilai rata-rata untuk kelas eksperimen sebesar 74,73 dan postes kelas kontol sebesar 66,66.

Berdasarkan hasil uji normalitas dengan menggunakan uji Lilliefors untuk kedua sampel diperoleh kesimpulan bahwa nilai pretes dan postes berdistribusi normal. Pengujian homogenitas data pretes dan postes pada kelas eksperimen dan kelas kontrol dilakukan dengan uji kesamaan dua varians diperoleh kelompok sampel berasal dari populasi yang homogen. Data kedua sampel dinyatakan normal dan homogen sehingga layak dilakukan uji hipotesis.

Hasil pengujian hipotesis ditunjukkan pada Tabel 2.

Tabel 2. Hasil Uji Hipotesis Data Pretes dan Postes

\begin{tabular}{|l|c|l|l|l|}
\hline \multicolumn{5}{|c|}{ Data Pretes } \\
\hline Kelas & $\begin{array}{c}\text { Rata- } \\
\text { rata }\end{array}$ & $\mathbf{t}_{\text {hitung }}$ & $\mathbf{t}_{\text {tabel }}$ & Kesimpulan \\
\hline Eksperimen & 37,00 & \multirow{5}{|c|}{ Data Postes } \\
\hline Kontrol & 37,71 & $-0,321$ & 1,997 & $\mathrm{H}_{0}$ diterima \\
\hline \multicolumn{5}{|c|}{} \\
\hline Eksperimen & 74,73 & 2,65 & 2,0 & $\mathrm{H}_{\mathrm{a}}$ diterima \\
\hline Kontrol & 66,66 & 2,65 & & \\
\hline
\end{tabular}

Berdasarkan hasil yang diperoleh dapat disimpulkan bahwa terdapat pengaruh penggunaan model pembelajaran kooperatif tipe GI 
investigation terhadap peningkatan hasil belajar siswa.

\section{Pembahasan}

Penelitian ini dilakukan di kelas

$X$ pada dua kelas yang diberikan perlakuan yang berbeda, dimana kelas kontrol diberikan pembelajaran konvensional dan pada kelas eksperimen diberikan pembelajaran model pembelajaran kooperatif tipe GI pada materi pokok suhu dan kalor di SMA Negeri 1 Percut Sei Tuan. Hasil penelitian menunjukkan bahwa rata-rata nilai postes di kelas eksprimen lebih tinggi daripada rata-rata nilai postes di kelas kontrol. Hasil ini memberikan informasi bahwa ada pengaruh yang positif dari model pembelajaran kooperatif tipe GI dalam meningkatkan hasil belajar siswa pada pelajaran fisika. Salah satu hal yang membuat hasil belajar di kelas eksperimen lebih tinggi daripada kelas kontrol adalah adanya penggunaan alat eksperimen yang digunakan dalam setiap proses pembelajaran untuk menunjang pengetahuan yang lebih tentang konsep materi suhu dan kalor. Rata-rata nilai sikap dan psikomotorik siswa semakin baik dalam setiap pertemuan. Setiap awal pembelajaran peneliti menyampaikan tujuan dan memotivasi siswa, peneliti memotivasi siswa dengan memberikan tujuan pembelajaran yang akan dicapai oleh siswa. Untuk kegiatan inti, peneliti menjelaskan prosedur pembelajaran pada siswa dengan membagikan LKS serta menugaskan siswa untuk melakukan investigasi (penyelidikan) terhadap suatu materi. Setiap kelompok melakukan percobaan sesuai petunjuk yang ada pada LKS. Kegiatan ini menuntut peneliti berperan sebagai observer yakni pengamat untuk menilai bagaimana sikap dan keterampilan siswa sesuai dengan lembar observasi yang disiapkan selama melakukan percobaan. Setiap kelompok mengumpulkan data yang diperoleh dari pengukuran ketika melakukan percobaan. Kegiatan ini peneliti berperan dalam membimbing siswa melakukan percobaan, menganalisis, dan mengasosiasi data tersebut sebagai bahan untuk presentasi. Untuk melihat berhasil atau tidaknya kegiatan pembelajaran, peneliti meminta beberapa kelompok untuk mempresentasikan hasil karya mereka dan kelompok lain diminta untuk menanggapinya. Fase akhir yang dilakukan yakni peneliti meminta siswa untuk memberikan kesimpulan dari materi yang telah di percobakan dan peneliti menyempurnakan. Kendala yang dihadapi saat menerapkan model ini yakni karena kurang memadainya alat dan bahan yang digunakan dalam praktikum, juga kurang terkoordinirnya kelompok yang dibentuk selama pembelajaran. Untuk mengatasi masalah ini, maka peneliti mengupayakan dengan membawa alat dan bahan praktikum pribadi untuk digunakan siswa selama pembelajaran serta mengubah beberapa kelompok dengan meminta saran dari guru kelasnya. Semua kegiatan ini dilakukan agar penggunaan model pembelajaran kooperatif tipe GI dapat diterapkan dengan baik.

Peningkatan rata-rata hasil belajar siswa yang diajar dengan model pembelajaran kooperatif tipe GI juga telah dilakukan oleh peneliti terdahulu seperti Simanjuntak (2014), Maisyarah (2014), Harahap (2014), dan Yasemin, dkk (2010). Berdasarkan hasil penelitian mereka didapatkan bahwa melalui model pembelajaran kooperatif tipe group investigation hasil belajar fisika siswa meningkat, dan dibandingkan dengan pembelajaran konvensional. 


\section{KESIMPULAN DAN SARAN Kesimpulan}

Berdasarkan hasil penelitian yang diperoleh nilai rata-rata siswa di kelas eksperimen yang menggunakan model pembelajaran kooperatif tipe GI lebih baik dibandingkan pembelajaran konvensional. yang artinya ada pengaruh yang signifikan antara hasil belajar siswa yang menggunakan model pembelajaran kooperatif tipe GI terhadap hasil belajar siswa pada materi pokok Suhu dan Kalor di kelas X semester II SMA Negeri 1 Percut Sei Tuan T.A 2015/2016.

\section{Saran}

Berdasarkan hasil penelitian dan kesimpulan yang dikemukakan maka untuk tindak lanjut penelitian ini, peneliti mempunyai saran kepada guru atau calon guru dan peneliti yang ingin menggunakan model pembelajaran group investigation sebaiknya mempersiapkan alat dan bahan yang baik untuk kegiatan praktikum. Karena kelengkapan dan kelayakan alat dan bahan di sekolah sangat mempengaruhi berhasil atau tidaknya pembelajaran dengan model ini. Untuk pembagian kelompok harus lebih dimaksimalkan atau rekomendasi oleh guru mata pelajaran dengan kelompok yang sudah ada sebelumnya.

\section{DAFTAR PUSTAKA}

Arends, R., (2008), Learning to Teach, Pustaka pelajar, Yogyakarta.

Depdiknas, (2006), Permendiknas No.22 Tahun $2006 \quad$ Tentang Standarisasi Sekolah Dasar Dan Menengah. Depdiknas, Jakarta.

Maisyarah, S. dan Ginting, E., (2014), Pengaruh Model Pembelajaran Kooperatif Tipe Group
Investigation (GI) Berbasis Peta Konsep terhadap Hasil Belajar Siswa pada Materi Pokok Usaha dan Energi di Kelas VIII semester Ganjil SMP N 9 T.Balai, Jurnal Inpafi, Vol 2, No 2:180-188

Muhibbinsyah, (2003), Psikologi Pendidikan dengan Pendekatan Baru, PT Remaja Rosdakarya, Bandung.

Priastuti, (2015), Pengaruh Model Pembelajaran Kooperatif Tipe Group Investigation (GI) Terhadap Hasil Belajar Siswa Pada Materi Pokok Besaran Fisika Dan Satuannya Di Kelas X Semester I SMA Negeri 1 Tanjung Tiram Batubara, Skripsi, UNIMED, Medan.

Sakinah, F. dan Purwanto, (2014), Pengaruh Model Pembelajaran Kooperatif Tipe Group Investigation terhadap Hasil Belajar Siswa pada Materi Pokok Suhu dan Kalor Kelas X SMA Negeri I Perbaungan, Jurnal Inpafi, Vol 2, No 3:84-88

Sudjana, (2005), Metoda Statistika, Tarsito, bandung

Simanjuntak, S. dan Simanjuntak, M., (2014), Pengaruh Model Pembelajaran Kooperatif Tipe Group Investigation (GI) Berbantuan Media Komputer terhadap Hasil Belajar Siswa pada Materi Pokok Listrik Dinamis di Kelas X Semester II SMA Negeri 10 Medan T.A. 2013/2014, Jurnal Inpafi, Vol 2, No 4:97-104 
Yasemin, Kemal, Ataman, dan Umit, (2010), The Effect of Two Cooperative Learning Strategies on the Teaching and Learning of the Topics of Chemical Kinetics, Journal of Turkish Science Education, Volume 7, Issue 2:52-65

Wahyuni, D., Fihrin, dan Muslimin, (2014), Efektivitas Model Pembelajaran Kooperatif Tipe Group Investigation terhadap Hasil Belajar Fisika pada Siswa Kelas XI MA Alkhairaat Kalangkangan, Jurnal Pendidikan Fisika, Vol. 2 No. 1 ISSN 23383240. 